() ЕУСПб, 2021. ISSN 2310-3817. Vol. 11, No. 1 c. 131-155

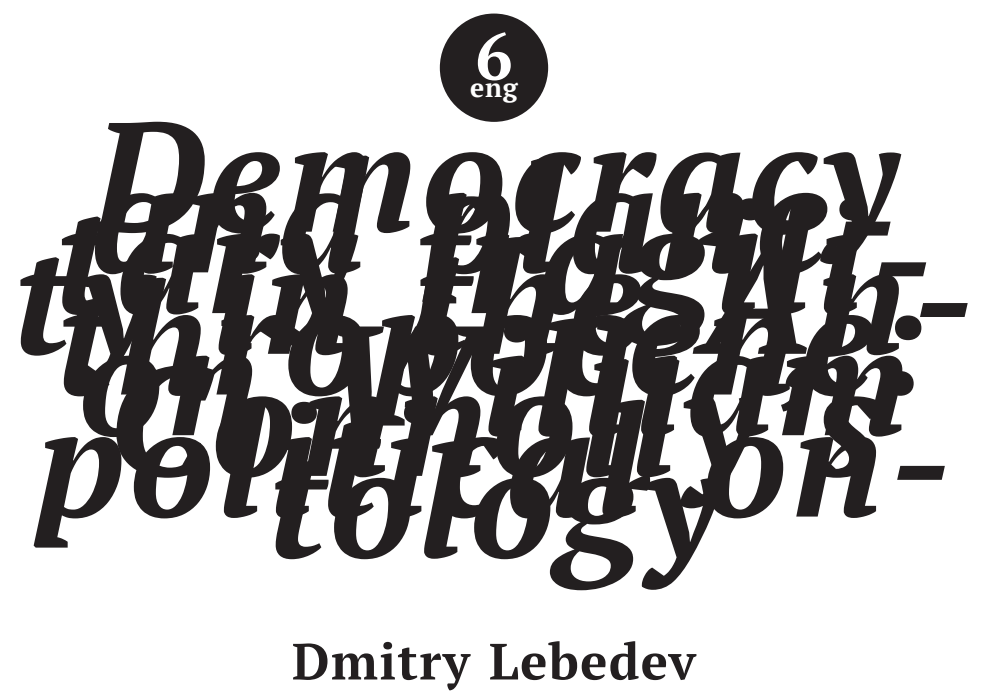

PhD Candidate

"Stasis" Center for Practical Philosophy

European University at St Petersburg, Gagarinskaya st., 7, St Petersburg, Russia

E-mail: dlebedev@eu.spb.ru

\title{
Democracy and Planetary Fragility in the Anthropocene: on William Connolly's Political Ontology
}

\begin{abstract}
:
As climate change rapidly intensifies, political theory urgently needs to respond to the shock of the Anthropocene and bring nature back to politics. William Connolly's work is a paradigmatic

example of such a theory that actively emphasizes the role nonhuman forces play in the social and political world and the discontinuity this emphasis brings to political theory. Connolly underscores fragile resonances between nature and culture and productively problematizes a human-centric vision of politics.

However, while interrogating how contemporary political
\end{abstract}


conjuncture catastrophically increases planetary fragility, he still insists on the continuity of his vision for democratic pluralism

that this very conjuncture fundamentally puts in question.

Thus, Connolly's type of post-anthropocentric ontology remains rather inconsistently connected to explicitly political concerns.

This article aims to clarify this connection. On the one hand, it shows how his brand of democratic politics that answers to the challenges of the Anthropocene presupposes a heightened degree of political negativism and universalism that used to be excluded from this politics. On the other, it demonstrates how the discontinuities in ontology must be simultaneously thought of as the discontinuities in established political theorizing and to continuously interrogate the very conjuncture that reveals the relevance of these ontological and political discontinuities.

\section{Keywords:}

Democracy, Anthropocene, negativity, micropolitics, conjuncture

\section{Introduction}

The Anthropocene: this notion has become common intellectual currency, indicating the threshold we as a species have crossed by unleashing our productive and extractive energies to such an extent that the whole of Earth is now in disarray. This notion is certainly scary - and vague. Its scariness comes from the very real possibility of the planet being uninhabitable in a span of a few generations: let climate change run away with itself and you will end up with a chain reaction of natural and technological catastrophes. However, if one intends to do something, the notion's vagueness comes to the fore. Who is this culpable Anthropos exactly? Does it possess a full identity that can be identified as a unified party in battle with nature? Alternatively, is it divided in itself - and so an explicitly political and democratic interrogation must ensue? Democratic theory as we know and practice it today cannot but start with the latter assumption, being historically allergic to the Platonic politics of the One and oriented toward forms of action that counter the drives to bring about this illusory unity and destroy (mostly human) plurality. But how come that this mostly human plurality - with its democracies, welfare states, neoliberalisms, social movements, and so on - is today so actively engaged in the destruction of mostly nonhuman plurality of plants, animals, glaciers, forests, and perma- 
frost? What should political theory do to overcome the narrowness of its traditional gaze?

We may call one way of dealing with this predicament integrationist. Roughly speaking, the Anthropocene's growing pains can be integrated into the liberal-democratic institutional framework and addressed therein. One can proceed according to the normative ideal of sustainability. Thus, the progressive integration of "green" issues looks a bit like the progressive extension of suffrage or human rights. If we are deliberative democrats, these issues should naturally be channeled and amplified by the institutions and norms of deliberative democracy (Dryzek and Pickering 2019). Deliberation that is concerned with non-violent communicative resolution, the moral legitimation of political decisions, and the presumable diffusion of power relations seems like the way to go lest we let the world plunge into violent social and political disorder arising from the natural transformations, dramatic lifestyle changes, and climate migration. If, however, we suspect that this deliberation might obscure certain power games and indirectly justify social exclusion (for example, of the indigenous groups whose dependence on the Earth systems is huge but whose access to the practices and knowledge of deliberative decision-making is low), we might opt for a more confrontational style of politics. Today, liberal critics of such a style pejoratively call it populism. On the other hand, notable opponents both of liberal incrementalism in policy and deliberative democracy in theory such as Chantal Mouffe have long advocated this conflict-driven type of politics, postulating inter-human antagonism as the essence of the political. Thus, environmental issues can figure as particular demands formulated by a popular political subject that contests hegemonic powers. Mouffe's (2020) recent calls to rally under the Green New Deal slogans popularized both in the US and the EU is an example of how radical democratic political theory includes the Anthropocene as a political issue into its theoretical framework. However, in both cases, nature is still a more or less politically external factor or element that is integrated into the continuity of this or that modality of political action that have been inherited from an era when the issue of the Anthropocene was not that pressing - both politically and theoretically. One might wonder whether the disruptive character of what we still call nature today is fully recognized here. In other words, this type of political theorizing for the Anthropocene remains, so to speak, too anthropocentric.

There is also a more delicate way of dealing with the issue of the Anthropocene without totally letting go of the aforementioned 
continuity of political theory and action. Recently, Lars Tønder suggested to view the Anthropocene and its challenges as an opportunity to rethink political theory and its guiding ambitions, to theorize politics "in a world that no longer adheres to the age-old distinction between the human and the nonhuman" (2017: 130). The Anthropocene reveals how far human life, including its messy politics, is constituted and mediated by a whole range of nonhuman entities and forces. Think of COVID-19, smog, forest fires, lead molecules, and algorithms for speed-trading. Perhaps it is time to attend to the resonances, intertwinements, entanglements, and mediations that operate between human and nonhuman actors and forces.

These preliminary remarks reveal the fact that there exists a certain theoretical bind. On the one hand, political theory inherits and strives to retain a focus on certain forms of civic action. On the other, it is also pushed by the unfolding events of the Anthropocene to leave behind the bios politikon exceptionalism and reshuffle its ontological premises. There must be both continuity of "old politics" and discontinuity inaugurating "new politics," both political theory and post-anthropocentric ontology. How do they relate? Moreover, in times when established liberal democracies find it so hard to implement any urgent climate policies and are constantly at risk of being overwhelmed either by climate-denying nationalism or by authoritarian, Chinese-style climate mitigation, it is indeed urgent to theorize a democratic break from this political impasse. At the same time, theory must stay alert to the dynamics of natural processes that are so obviously not (and have never been) within our control. How to continue democratic contestation while being affected by the discontinuities in our modes of thought and action that climate change initiates? How to accept the loss of human exceptionality and agency while still insisting on the need to constitute something like a political subjectivity, a necessarily plural demos?

We must now turn to the works of William Connolly, precisely because he theorizes from within this bind and remains committed to both of its poles. For decades, Connolly has been examining the forms of civic action that disclose, disrupt, and displace our hierarchized and settled identities and institutions without, however, insisting on the revolutionary and utopian overhaul. At the same time, in the last twenty years this orientation has itself been disrupted by his growing interest in life sciences, neuroscientific discoveries, and earth systems. A closer look at Connolly's theoretical development may reveal a certain logic articulated in what we 
described as political theory's continuity and discontinuity - and this logic may lead us to a renewed understanding of what counts as the political.

To justify the lengthy analysis of Connolly's work, we need to indicate several pivotal moments of his intellectual evolution. Connolly developed his own theories of democracy and pluralism partly in reaction to the pluralist tradition that dominated American political science in the postwar years, before the turbulence of the sixties and the rise of the New Left. Connolly was engaged with the New Left but did not drop the notion of pluralism. Instead, he dropped the connotations of this term: minimalist democracy where voters choose between political elites and the whole field of politics is dominated by the plurality of lobby groups and private interests. His own work on pluralism and agonistic democracy came to fruition in the 1990s, this time in a critical exchange with communitarian, secular-liberal, and deliberative trends in political thought that had acquired great prominence after the collapse of the Soviet Union (represented, respectively, by such figures as Taylor, Rawls, and Habermas). His chief concern was blurring the line between ethics and politics, arguing in favor of the agonistic and pragmatic technics of the self - strongly influenced by the philosophies of Michel Foucault and Gilles Deleuze. Connolly's vision was civic ethics and a vibrant political culture whose real-life manifestations were the politics of identity recognition and minoritarian social movements that rose from the experiences of the New Left.

However, already in 1991's Identity/Difference Connolly attempted to inform democratic theory with some naturalist considerations that highlight the political significance of the material world's volatility and fragility. From 2002's Neuropolitics onward, his engagement with the neuro- and life sciences has become more extensive and acute, bringing him closer to the new materialist camp in contemporary thought that includes, among others, Jane Bennett, his colleague at John Hopkins University. In the 2010s, the Anthropocene as a political problem occupies a central place in his texts, especially in The Fragility of Things (2013) and Facing the Planetary (2017b). They are indeed a concentrated attempt to think a pluralist democratic culture responding to the shock of the Anthropocene. It is important to take a closer look at his work precisely because it is a paradigmatic case of political theory meeting current discussions on nature and non-humanity around and within us (think again of COVID-19). Thus, he aligns not only with explicitly political theorists such as Hannah Arendt, Sheldon Wolin, Bonnie Honig, but also with Bruno Latour, Jane Bennet, Timothy Morton, Catherine Heller, 
and other thinkers on the end of human exceptionalism. With this amalgamation, Connolly also transcends a quite pronounced American focus of his earlier work and becomes more attentive to other global intellectual voices and traditions.

In what follows, we will look at the several layers through which democratic theory and post-anthropocentric ontology relate to each other in Connolly's work. In the first part, it is necessary to follow how Connolly's brand of democratic theory developed by centering on the notions of pluralism and agonism and the way his line of reasoning opens up a space for naturalist ontology to emerge and gain political salience. In the second, we will examine the structure and inner logic of this ontology, which Connolly himself named immanent naturalism. This naturalism emphasizes immanent affective processes that link nature and culture in a kind of dynamic biocultural milieu to reveal its inherent fragility and universal character, which Connolly later conceptualizes through the notion of the planetary. This contemporary condition can be characterized as "planetary fragility" with multiple politico-strategical implications. The third part will be devoted to these implications. On the one hand, Connolly describes his brand of democratic pluralism and ethical micropolitics with a certain continuity and permanence that can be considered a hallmark of the social movement era. On the other, Connolly's own politicized naturalism of planetary fragility reopens a certain universalistic horizon that radically disturbs the clarity concerning specific modes of political action inherited from the previous era of "old politics" in which the issue of the Anthropocene was not paramount. The fourth part will engage the critique of Connolly's political ontology with a focus on Adrian Johnston's transcendental materialism that aims to think, partly in line with Connolly's universalist planetary fragility, the resurfacing of a political subject through the notions of negativity and transcendence. Politically, this would allow Connolly to hold onto the vision of planetary fragility while radically broadening the scope and number of forms of political action. The fifth part will offer a series of conclusions concerning the logic, according to which the disintegration of ecology and the collapse of the nature/culture division rearticulate what counts as the political today and the stakes for political theory. Connolly's oeuvre and his recent interventions in contemporary conjuncture offer a glimpse of a theory of action that derives its legitimacy and negativist impulse from this strange "attractor" that we called planetary fragility and reinvents itself as paradoxical yet operative revolutionary pragmatism. 


\section{Politics in Search of an Ontology}

In the public imagination, the postwar years in the West are frequently portrayed as a fascinating time of stability and prosperity, when out of the horrors of Fascism and the Great Depression a new social democratic consensus proved to be victorious. This trente glorieuses was eventually crushed by neoliberal reaction but still haunts political minds as an era of unimaginable stability and prosperity (did not Donald Trump want to revive something of these decades' spirit?). At the theoretical level, political thought in those postwar years, in the United States at least, was dominated by a discourse on pluralism and minimalist democracy: plurality of interest groups, periodic elections, legitimate opposition, the rotation of elites in government and a surprising silence of anti-systemic dissent all contributed to a certain stability and resilience of the Western political system. During the political upheavals of the 1960s and 1970s, civil society "rediscovered" itself in a variety of bottom-up social movements that tended to articulate demands that the then-political culture had a hard time to process. Connolly's theoretical coming of age was largely determined by this transformation, when the landscape and legitimacy of the hitherto respectable political science was shattered and a whole range of issues at the borderline of politics and ethics became visible. His subsequent work was devoted precisely to the navigation of this borderline: he wanted to give new meaning to the term pluralism, and the eruption of a variety of social movements and cultural identities proved to be a fortunate background for such an enterprise.

The rediscovery of civil society, that is, of its political power rather than mere economic activity as in the Hegelian system of needs, comprises the background of what Connolly would theorize as agonistic democracy, in dialogue with and in contradistinction to the then-fashionable communitarian and deliberative accounts of democratic polity. In Charles Taylor's communitarian thought, with its concern for the shared moral order according to which identities might authentically express and realize themselves, Connolly (1985) sees the quest for a too-harmonized world in which a host of disciplinary and control techniques might still dominate those existential strivings that do not fit a given set of personal and communal identities. Likewise, he argues against consensus-oriented liberals such as John Rawls and Jürgen Habermas that "no practice of public reason, deliberation, or procedure suffices to govern political life" (Connolly 2002a [1991]: xxii). We do not and cannot put aside our ethical and existential orientations to universally conceive of a just 
society, as is done in the Rawlsean original position. This plurality of spiritual dispositions does not square well with the central emphasis put on the constitutional protections of legal persons and the role of seemingly neutral institutions like the Supreme Court. Similarly, when we strive to reach shared moral universalism by dialogical means and communicative procedures, as in Habermas's neo-Kantian ethics, it is still impossible to settle our ontological disagreements and just focus on the epistemological problems of political participation and the inscription of plural worldviews. Any universalism ultimately breaks down. Connolly's positive program is known as agonistic democracy, its other key proponents being Chantal Mouffe and Bonnie Honig.

What is this agon? It is, primarily, the politicization of cultural practices that, in a traditional liberal worldview, are shielded within the private sphere. Connolly, as it were, continues Arendt's insights into the public sphere's mode of functioning as a space of contest constituted by the interactions between singular individuals and their worldviews. At the same time, he collapses her strict divide between the public and the private. What used to be the private, with its spiritual dispositions, existential hopes and fears and invisible violence, is now a ground from which politicization proceeds. Bracketing ontological disagreements in favor of some ideal and transparent public sphere is actually impossible, and what we could call "democratic politics" is both democratic and political only to the extent that it aspires to engage this plurality and work upon it pragmatically. As Connolly explains in Identity/Difference, agonistic democracy is "a practice that affirms the indispensability of identity to life, disturbs the dogmatization of identity, and folds care for the protean diversity of human life into the strife and interdependence of identity/difference" (Connolly 2002a [1991]: x).

Connolly seeks not simply a medium of engaging, pacifying, and domesticating already-existing cultural pluralism, but "an active pluralization of ethical sources in public life" (Ibid.: xxi). In the historical context of Reagan's "moral majority," ACT UP, debates on abortion, gay rights, feminism, and other issues still dividing the public not only in the US but also in countries like Russia, this ethical turn was quite pertinent. It sought to politicize, diffuse, and disturb fundamentalist cultural trends, counter them with new affirmative ethics that do not shy away from debates and contestation and remain alert to the problematic voices within itself, that is, alert to the tendencies to become a closed and disciplinary system itself. As Connolly surmises, "maybe the drive to the knockdown argument in ontopolitical interpretation is a corollary to the drive to 
fundamentalism in political life. Perhaps by pondering more closely the irreducible character of ontopolitical contestation we can move the pluralist imagination into domains that have heretofore escaped it" (Connolly 1995: 16). Therefore, if we want to make a democratic argument, we must start with some way of envisioning the world in which any ontology is inherently contestable, from secular neo-Kantianism to Buddhism, evangelicalism, or political Islam. In sum, we begin with the already-existing pluralism of worldviews and contest their pretentions to ultimate truth, that is, pluralize and disrupt them from within.

In Identity/Difference, Connolly argues for a "relational" social ontology that "does not say that the world is chaos, but that every organization of the self and the world meets with resistances as well as with variable degrees of receptivity and organizability" (2002a [1991]: 225-26). Thus, identity-formation is indispensable to politics, but democratic politics must see this identity as punctuated and disrupted by difference operating within it. In short, democratic politics has an intrinsic ethical dimension irreducible to state politics, periodic elections, communitarian order or norms of communication. As Connolly states, "to confess a particular identity is also to belong to difference" (Ibid.: xiv). This is, of course, a desired state of affairs that he conceptualizes as "agonistic respect" - "a reciprocal virtue appropriate to a world in which partisans find themselves in intensive relations of political interdependence" (Ibid.: xxvi). His other master term to designate this ethics is "critical responsiveness" (Ibid.: xxviii).

What is this difference, though? It can be the human Other, nonhuman Other - or something inhuman within a human agent. As if anticipating his later full-blown naturalism, Connolly speaks of "the contingency of life" and "the fragility of things" that have become more pronounced in our late-modern time but cannot be dealt with politically if we "postulate either the world's predisposition to some mode of mastery (capitalist or socialist) or some inner harmony in being available to those who will listen for it attentively" (Ibid.: 226). Any plan to dominate nature or to recreate communitarian holism runs up against the troubling fact of ontological volatility in which natural and cultural determinations blur into each other. The contingencies and indeterminacies impregnate both cultural and natural processes to such an extent that one should better speak of their mixture, or, bioculture. Difference, this negative force disturbing full identity, suddenly appears as a natural event. In 1993, in a collection edited by Jane Bennett and William Chaloupka, Connolly says: "If a human actor is one who makes a difference in the world 
without quite knowing what it is doing, then germs, volcanoes, crocodiles, and whirlwinds have some of the characteristics of actors too" (1993: 205-06). Now, his ethico-political concern for difference reinvents itself as political attention to these uncanny "voices from the whirlwind" that mark what we now call the Anthropocene.

\section{Naturalism and Planetary Fragility}

Connolly develops a full-throttled account of biocultural politics in his key book, Neuropolitics, published in 2002. There, he makes his most detailed and elaborated effort to engage contemporary neurosciences, thus joining a number of other authors in what has become known as the "affective turn" in philosophy and critical theory. Like other notable representatives of this turn, especially Brian Massumi, Connolly draws heavily on the "minor" tradition in Western thought, encompassing such figures as Baruch Spinoza, Henri Bergson, Alfred North Whitehead, Friedrich Nietzsche, Isabelle Stengers, Ilya Prigozhine, and Gilles Deleuze. At the same time, Connolly's background in political science and political theory allows for quite a peculiar form of turning to affectivity. More precisely, his engagement with neurosciences and affect theory is informed by an idea to enrich pluralist democratic culture and make it more vibrant and less focused on a disembodied, rationalist side of politics. What he seeks in neurosciences and their attention to pre- and non-cognitive affective experiences is a way to bring nature into political theory as a contingent and unpredictable quasi-determinant that upsets any attempt to eliminate contestation and contingency from democratic politics. As Connolly argues in Neuropolitics, "without affect, thinking would lack creativity; with it, thinking is invested with the volatility of nature" (2002b: 67).

Connolly names his ontological paradigm immanent naturalism. His nature is a volatile mix of immanent biocultural resonances without any teleology. In Neuropolitics, Connolly examines how consciously, culturally, and intersubjectively mediated thinking and affective sensations work in parallel fashion, being irreducible to each other but also somehow inseparable. He depicts a layered picture of culture in which constant resonances between brain, body, and environment operate at multiple speeds and in different temporalities. This way of thinking culture is a "third" one between eliminative biologism that tends to reduce everything to the work of egoistic genes and those idealistic accounts that adopt a mechanistic view of nature but insist on the symbolic power of more or less denatured social constructivism. As Connolly claims, "classical distinctions of 
kind between culture and nature now become translated into interacting layers of biocultural complexity. For it is not only in human culture that perception, interpretation, unpredictability, and history occur. They occur, to varying degrees of complexity and on different scales of duration, in several nonhuman processes as well" (Ibid.: 61). The line separating nature from culture becomes more porous and, strictly speaking, elusive. Thus, nature cannot be reduced to the ironclad mechanistic laws and culture is no longer a sole site in which freedom, creativity, and contingency might emerge.

In Neuropolitics, Connolly's focus on political pluralism is, as it were, doubled and complicated by the addition of "natural" disturbances that extend ontological multiplicity of beings in their incessant and unruly becoming. Strictly speaking, his bioculture is not an identity between what used to be "culture" and "nature." Rather, it looks more like a series of contingent events that cannot be characterized as merely "natural" or "cultural" and that produce new singularities and multiplicities. Moreover, bioculture is strictly opposed to any philosophical monism, thus adhering to a vision developed by William James, one of Connolly's main intellectual heroes. In A Pluralistic Universe, James writes: "Nature, more demonic than divine, is above all things multifarious. So many creatures that feed or threaten, that help or crush, so many beings to hate or love, to understand or start at - which is on top and which subordinate? Who can tell?" (1987: 640). While monism seeks the Absolute in order not to be crushed by nothingness, this ontological pluralism investigates some connections and disconnections between things of the world and out of this experience develops its spiritual sensibilities. Thus, this kind of naturalism betrays a surprising homology with Connolly's theory of political subjectivity detailed in Identity/Difference - spiritual, affirmative, attentive, pragmatic, evading claims to Absolute knowledge and ethical fundamentalism.

This line of reasoning is further developed in The Fragility of Things (2013) and Facing the Planetary (2017b). However, there is a slight, yet crucial change of emphasis. Connolly's inquiry into ontological multiplicity of beings and events is complicated by employing the notion of the planetary. Now he puts more stress on the universality of the immanent cosmos that is inherently unstable and productive of the ontological plurality noted above. In Facing the Planetary, Connolly defines the planetary as "a series of temporal force fields, such as climate patterns, drought zones, the ocean conveyor system, species evolution, glacier flows, and hurricanes that exhibit self-organizing capacities to varying degrees and that impinge upon each other and human life in numerous ways" (2017b:4). 
And in The Fragility of Things, he claims that "the human estate is both imbricated with and periodically overmatched by a cosmos composed of multiple, interacting force fields moving at different speeds" (2013: 7).

With the notion of the planetary, Connolly describes a kind of universality that is inherently disruptive, estranging, and perceivable primarily as fragility. As Deleuze said apropos Nietzsche (the major influence on Connolly) and his philosophy of nature, "multiplicity is the inseparable manifestation, essential transformation and constant symptom of unity" (Deleuze 1983: 24). In its constant becoming, this ontological plurality remains precariously unified. This unity is inherently fragile. Perhaps the condition Connolly theorizes can be called planetary fragility. However, this condition needs to be attended to. If we pay attention to the phenomena ranging from ocean conveyor systems to the biochemical processes in the soil and to bacteria inhabiting our homes, then to be human means "to be organized by a host of nonhuman processes and to be entangled with others" (Connolly 2013: 49). There is some negativity in it since the attunement to the planetary's volatility and to the precarity of our entanglement with it is also the moment when the world's fragility and the risks of losing it are at full display. Nature itself "is incomplete in that every mode of self-organization involves external connections and internal constraints that enable it to be this and not that" and "in ways that periodically allow perturbations from elsewhere to trigger creative processes within or between entities that exceed the sufficiency of any closed explanation" (Connolly 2017b: 48). What is normally called nature is much more creative, unpredictable, changeable, and contingent than is supposed by those "sociocentric" theories that elevate human agency and "interpret or explain social processes by reference to other social processes alone" (Ibid.: 15).

For Connolly, to bring a nonhuman element into political thought is not to flatten all ontological hierarchies but to disrupt them. This attempt to disorder the all-too-human vision of politics and culture is meant to work as further politicization of the very question of what counts as the political today. It is indeed a radical extension of the scope of political theory that, to follow Bruno Latour's (2019) terminology, reaches beyond the opposition of global and local to a situated sense of being earthbound, of inhabiting an uncanny space in which multiple agencies infiltrate each other and there is no master either of human or supernatural kind. At the same time, if Latour pictures planetary fragility as a new political attractor that moves us beyond our inherited political categories, including those 
of the Left and the Right, here the situation is more complex, at least in the politico-ontological perspective.

For Connolly, what is called the planetary never was a stable background of human affairs (neither was it for Latour, but this is a different subject). It might be a political attractor today, but it surely was, is, and will be for some predictable time a strange and fragile disruptor of what we as political actors might bring about. This is why Connolly (2017b: 25) is reluctant to use the term Capitalocene since it implies that only with capitalism have we entered an era of planetary fragility. Prehistoric extinctions, deforestations conducted by Amerindians, indigenous Australian tribes, and Middle Age Europeans cannot be attributed to the powers of extractive capitalism as we know it today. Of course, the Right frequently uses this argumentation: look, the earth has always been unpredictable, climate has always been changing, we have seen this before and yet the world still stands, more prosperous than ever. At the same time, the intensity with which human and nonhuman processes impinge upon each other and yield new contingent events has ostensibly increased today. In the Anthropocene, events such as droughts, forest fires, new viruses, extinctions, melting permafrost are increasingly perceived as a part of the major shift in the human condition as such. What conceptual nuances might clarify this tension?

In his most recent book to date, Climate Machines (2019), Connolly goes even more Deleuzean than before. To make sense of the Anthropocene, of its continuity with certain human practices, its general natural volatility, and its discontinuity that the condition of planetary fragility indicates, he employs the notion of an abstract machine. As he explains, "an abstract machine, in the sense deployed here, includes moving, morphing planetary complexes that exceed the power of the ensemble of forces and agencies that constitute it" (Ibid.: 50). As we remember from A Thousand Plateaus, there are different abstract machines that can overlap and even conflict in their deployment, as when a potentially revolutionary abstract machine that opens new ontological connections is overwhelmed by abstract machines "that perform totalizations, homogenizations, conjunctions of closure" (Deleuze and Guattari 1987: 514). Therefore, while Connolly calls for "ecologically attentive notions of the Anthropocene as an abstract machine irreducible to a single sovereign authority" (2019: 60), he nonetheless describes a "conjunction" between the contingent and volatile planetary machine and the capitalist-extractivist-consumerist machine of our times. The latter's homogenizing operation may be said to produce and reinforce a certain fragile planetarily existence that does not open 
new connections to the world and the identities living therein, but rather blocks this opening. Yet, this machine, this regime "often finds itself searching and groping in the dark as new events unfold or erupt. It is thus never exempt from creative practices of politics that infuse its institutions and pursuits" (Ibid.: 51). Ultimately, this "conjunction" is our conjuncture: instead of the planetary fragility that is supposed to be the ontological plane on which nature, culture, political identities, ethical dispositions, and technical objects form contingent connections and new biocultural assemblages, "we" have a deadlock in which fragility reveals itself as an imminent series of catastrophes, identity closures, continuing oil drills and spills, democratic fatigue, authoritarian and eco-fascist reactions and the failure to imagine the end of capitalism.

\section{Micropolitics and Beyond}

Planetary fragility displays both ontological continuity - there has always been this fragility and biocultural contingency-and radical discontinuity, which is manifested in the Anthropocene conjuncture that reinforces this fragility to a catastrophic degree. How does one translate this predicament into politics? Which modalities of political action can or should cut across it? If we look at how Connolly conceptualizes political action for the Anthropocene, one suspects that there is more continuity with his ethical and movement-based approach to politics of the earlier work than the rupture of the Anthropocene warrants. In what follows, we will briefly present the main tenets and possible inconsistencies of this approach that Connolly calls micropolitics.

Micropolitics is an ethical project that Connolly borrows from Foucault and Deleuze and invests with overt democratic considerations. In Neuropolitics, he wonders: If affect "becomes organized into habits of feeling and judgment that flow into the intellect, by what means can this dimension of being be reeducated?" (Connolly 2002b: 76). Micropolitics, then, is "a cultural collectivization and politicization of arts of the self. Micropolitics applies tactics to multiple layers of intersubjective being. Because it is often practiced in competitive settings, it contains an agonistic element" (Ibid.: 108). His favorite examples include experiments with media such as film, physical exercises, and even “priming” one's dream life before sleep. These practices aim to challenge the established norms and forms of perception, including the perception of cultural and political differences. Generally, it is some sort of psychophysical gymnastics that alters the ways of seeing, feeling, and, if one is lucky, judging the 
world around. Connolly's micropolitics is a way to cultivate ethical sensibilities, especially those that are needed to care for our common habitat during the ecological destruction of the Anthropocene.

Why is micropolitics vital? In Identity/Difference, Connolly focuses on the paradoxical cultural-political dynamics whereby any identity construction is dependent upon a paradoxical external/internal difference that is time and again transformed politically into otherness to be excluded or repressed. Theoretically, this production of otherness can be extended from human minorities to nonhuman phenomena. To solidify one's identity by excluding a constitutive difference and turning it into otherness is technically akin to solidifying an identity of extractivist politico-economic community by rendering nature an immutable and disposable reserve. To mitigate against this production of human and nonhuman otherness, regular institutional action would not suffice. Micropolitics, then, is a conscious attempt to intervene in the affective and visceral register of cultural life. For Connolly, an economic pace drugged on an imperative of growth should be countered not only by deliberative arguments and democratic procedures but also by cultural techniques establishing and maintaining new sensibilities. Connolly describes the latter in poetic terms resembling New Age spiritualism: more "visceral attachment," more "existential gratitude," more "protean care," more "presumptive generosity" toward "the sweetness of life" and "the diversity of being." As he proclaims, "the objective is to stretch human subjective capacities by artistic and experimental means so as to respond more sensitively to other force fields" (Connolly 2013: 161). We must change democratic culture itself and, thus, micropolitics is this medium of change applicable to both "culture wars" and the Anthropocene.

Does this mean that micropolitics should be the only game in town? Sometimes one can get this impression, but Connolly's answer is certainly negative. Although micropolitics appears as mostly an individual affair, Connolly tries to align it with his vision of collective action. It is essential in that it works on "the visceral register of cultural life" as its artistic "practices operate between individual behavior and collective assemblages as they activate role shifts within institutional settings" (Ibid.: 125). Under ideal circumstances, it might crystallize in "rhizomatic complexes" of plural social movements operating well beyond the borders of nation-states. Thus, he makes a case for cross-cultural, multidimensional general strikes that he places under the rubric of "politics of swarming." As he explains, "the politics of swarming, then, is composed of multiple constituencies, regions, levels, processes of communication, and modes of action, each carrying some potential to augment and intensify the 
others with which it becomes associated" (Ibid.: 125). Politics of swarming might result in active pluralist assemblages within which we extend our cosmic sensibilities, develop creative political powers and keep ourselves alert to the new attempts to initiate a crackdown on the tendencies to pluralize the social. In one interview, Connolly lays out his strategic vision in these terms:

The strategic idea is to move through accentuation of attachment to the sweetness of life in an unruly world, to a variety of role experimentations that make a cumulative difference to the Anthropocene on their own, to more active participation in social movements, to renewed pressure on electoral politics, to a cross-country general strike that poses a series of stringent interim demands to states, corporations, churches, universities, international organizations, banks, consumers, and the like. (Ibid.: 185-86)

What this scaling up, as expressed by the italicized conjunction to, describes is nothing else than political subjectivation. However, is it not also seamless? One should look for potential problems at the ground level: Is not the "attachment to the sweetness of life" something that is only virtually present yet actually blocked within the conjuncture of the Anthropocene machine as Connolly depicts it? Gradual political subjectivation as a way to act at the planetary level (that is, at the level of universality) proceeds here from a certain positivity and fullness. Connolly seems to stick too tightly to the model of political action already elaborated thirty years ago (ironically, this was also the time when international action on climate change was aborted and the "merchants of doubt" started their active poisoning of the whole climate debate). Again, this is not to say that his ethical approach is outdated - we have already stated that it is more relevant than ever. Nonetheless, his focus on the contradictions of universal planetary fragility reveals that "an unruly world" constantly negates the very ability to attach meaningfully to it. Accentuating ethical positivity as the ground level of politics is itself put into question by the condition of planetary fragility, this attractor/disruptor that brings into its orbit all the existing modes of political action and radically disturbs their self-sufficiency and any potential antagonisms between them.

\section{Negativity and Transcendence}

So far, we have seen how Connolly's immanent naturalism has become an ontological ground for a specific type of political ethics. 
At the same time, it contains certain monistic characteristics that point toward a universal political dimension that is blocked by the conjunction of planetary fragility and the predatory capitalistic machine. Yet, Connolly is not a revolutionary. As he notes, "the point today is not to wait for a revolution that overthrows the whole system' because this 'system' is 'replete with too many loose ends, uneven edges, dicey intersections with nonhuman forces, and uncertain trajectories to make such a wholesale project plausible" (2013: 42). Therefore, in some cases it might be better to fight existing and eco-unfriendly consumption practices rather than engage in revolutionary and anti-systemic rhetoric and struggle. Perhaps Connolly's vision is close to such real-life movements as Extinction Rebellion: acting on the system's "loose ends" such as transportation (hence its blockage), exploiting the affective power of media images and aesthetic presentation, and radical enough in its modes of civil disobedience. Marxist critique, of course, would point out that it is too aesthetic, too middle class and metropolitan, too focused on individual ethical commitment and not political enough in the sense that it does not articulate a coherent vision of social and political transformation. In short, it is not socialist enough - the latter would imply some sort of transcendence of its aestheticized and ethicized mode of political pressure, a negative gesture toward the present conjunction of planetary fragility and destructive political economy.

Transcendence and negativity: these are two recurrent topics in the critique of Connolly. For instance, one might point out how ethical attention and critical responsiveness to the affective flows in the becoming of Connolly's substance-like bioculture require constant conceptual mediation and intentionality (Leys 2011). In other words, for ethics to be really invested in precognitive, microperceptual, and affective sensations it needs deep attention and preformed conceptual dispositions that are nothing other than partial transcendences of this affective vitalism. Likewise, for his agonistic mode of subverting identity closures to be politically effective, Connolly might need to depart from his "self-regulating immanent substance" through the labor of the negative, understood as a radical cleavage in the immanent naturalism's biocultural regularity (Wenman 2008). Otherwise, this ethical enterprise might remain reserved for those who already have the mental and organizational resources for this experimental undertaking. According to Lois McNay, Connolly does not articulate the logic of pluralization with that of deep and entrenched social inequality, and "whilst he may problematize essentialist notions of identity on one dimension, he reinstalls them on another through the quasi-naturalist idea of minoritarian 
becoming, which presents political mobilization as a spontaneous, unproblematic inevitability" (McNay 2014: 187). If Connolly seeks to restore creativity in politics and at the same time acknowledges the hegemonic blockage of this creativity's immanent sources (the "conjunction" we refer to above), then it is indeed necessary to posit purposive and intentional transcendence of the status quo as a moment of negativity.

One of the most consistent critiques of Connolly's political ontology has been developed by Adrian Johnston (2014). Johnston's sympathetic attack revolves around the issue of (political) subjectivity's emergence. For Connolly, a more detailed elaboration of bodily sensations and affective streams reveals "the indispensability and insufficiency of subjectivity to thought" (2002b: 71). As he insists, "subjectivity is not a ground of being; it is a formation" that finds "differential degrees of expression in numerous processes beyond the human estate that are entangled with it" (2013: 166). His ontology decenters and problematizes the human subject by pointing out its imbrications with nonhuman processes but sometimes at the expense of making it hard to imagine a self-reflexive political subject acting in a volatile world. Johnston's transcendental materialism, on the other hand, is explicitly concerned with this subjectivity's emergence out of an asubjective, contingent, historical, and more-than-deterministic nature. This is indeed a vision of nature that lies at the heart of Connolly's immanent naturalism but, for Johnston, Connolly never leaves the positive immanent plane, making it hard to account for an active and self-conscious subject that will actually change history. Johnston himself is more interested in "the surfacing of the negativities characteristic of denaturalized, more-than-material subjects out of the positivities of natural matter[s])" (2014: 17). As he notes, "transcendental materialism posits, in short, a self-sundering material Grund internally producing what (subsequently) transcends it" (2008: 61). The material (or natural, or nonhuman) constantly resurfaces but as a void in subjectivity that makes full identity structurally impossible - and yet, this void is nothing other than the locus of freedom. Thinking negativity amounts here to thinking the possibility of a free subject in an unruly and contingent world.

According to Johnston, Connolly's renewed materialism is too reluctant. On the one hand, Connolly insists on a certain autonomy of thinking and rejects eliminative physicalist accounts that reduce it to "dumb" brain matter. On the other, "he appears to retract/revoke this very freedom though simultaneously insisting on thinking's impinged-upon position relative to its physical ground (with the former stuck being perpetually 'affected' by the latter)" (Johnston 2014: 
304). By enmeshing thinking, culture, and politics in a web of natural processes and phenomena, "Connolly runs the risk of squelching the subject altogether” (Ibid.: 306). For Johnston, Connolly’s ontological pluralism is too monist; it stretches substance qua nature to such an extent that it becomes extremely hard to even determine a subject position from which such grand claims can be made.

However, is it true that Johnston's proximity to Connolly's immanent naturalism "is riven and marked by an unbridgeable divide" (Johnston 2014: 319)? Surely, Connolly rejects "rupture' between humanity and the rest of the world" but, at the same time, he also does not support "the idea of an organic fit between humanity and the world" (Connolly 2013: 148). He mostly allows for "tensions" between the two expressed at the affective level as vitality. Here, we might need to invert the terms. Connolly's positive vitality should be seen as negativity but, as it were, in slow motion. As Diana Coole (2000: 6) shows in her Negativity and Politics, this positive rendering of nonidentity and contingency can itself be described as negativity but expressed in different rhythms and tempos. In Connolly's account, negativity is associated with the immanent forces of becoming and is reconfigured as yet another tension and potentiality for new resonances between humans and nonhumans and further role experiments in politics. It seems that both Johnston and Connolly consider the way nature reveals itself in the realm of human affairs as essentially negative: it is, as we said, this great "disruptor" that manifests itself not only in external events but also as an internal split within the political subject. They highlight different degrees of this negativity (we can call them "strong" and "weak") and it seems that these gestures have more to do not with the way they see the general logic of natural and nonhuman affectivity, but with the implicit and explicit political preferences held by both thinkers. Everything revolves, then, around the passage from ontology to political theory.

Johnson's point that Connolly's ontology strongly pushes thinking "to jump the gap from philosophy to politics toward specific forms of the latter" (Johnston 2014: 299) contains a grain of truth. More specifically, even though Connolly acknowledges the importance of the macropolitical dimension, we cannot simply bypass his insistence that micropolitical experimentation in ethics merits more attention today. Thus, Johnston insists that bridging the gap between politics and ontology "in a dramatically different way, one aiming toward a revolutionary macropolitics rather than a reformist micropolitics, is at least as justified" (Ibid.: 299). Here there is an obvious risk of coming back to an eternal debate on the issue of reform versus revolution. 
But it will be truly disappointing if, after building new and complex models of the way nature permeates politics, we suddenly return to the old and ironclad models of political thinking. Our starting point was that the shock of the Anthropocene brings about discontinuity in political thought, that the contingency of matter shatters not only the human sense of exceptionality but also how to think the world politically. The preceding exposition of the Johnston/Connolly debate shows that this discontinuity amounts to a letting-go of the certainty concerning the privileged types of political action and subjects as well as distinctions inherited from an era of "natural stability." Otherwise, we are stuck with the integrationist model of thinking the politics of nature. Put differently, by presupposing that either deliberation, populism, reformism, or revolution is the surest way to go we thus define politics as something that goes essentially between historical human agents while the planetary fragility is again relegated to the role of a "too natural" background.

At the same time, we also declared that some continuity is crucial: the total breakdown of all established political categories is unlikely to thwart the dangers posed by and in the Anthropocene. Perhaps we must recall here a person to whom political thought is probably most heavily indebted: Niccolò Machiavelli. As Louis Althusser (1999) notes in his fascinating work Machiavelli and Us, it is with Machiavelli that political theorizing actively inserts itself into the conjuncture - inserts precisely because it is a rupture, a discontinuity - and henceforth contributes to its historical unfolding. Moreover, does Machiavelli's nature as fortuna not resemble this negatively charged planetary fragility we are exploring (this time not a woman, of course, but a kind of cyborg)? It is full of contingencies, unpredictable, even demonic - and yet indispensable to political action precisely because of these traits. Is his virtù as radical political virtuosity of combining different political actions and strategies not in relation and response to an inherently uncertain conjuncture, something that is called forth by the volatility and fragility of the Anthropocene? Perhaps this is where the real continuity of political theory lies: it is an attachment not to the sweetness of life or to the grand revolutionary subjectivity but to the problematic and potentially catastrophic conjuncture that constitutes the continuity of political thinking. A historical rupture registered by changing ontological presuppositions makes political theory radically reinvent itself. While Machiavelli responded with his pragmatic and simultaneously powerful virtù to the advent of the sovereign state system, thinking the Anthropocene as the Event of our times invites a similar response that seeks to measure its power 
against the malleable fortuna of planetary conjunction. Furthermore, it is in this virtuoso attachment to the Event that we might look for a principle of mediation between "weak" and "strong" negativity in question. Luckily, Connolly's latest theoretical interventions seem to go precisely in this direction.

\section{Democracy: Pragmatic and Revolutionary?}

Twenty years ago, in his article entitled "Assembling the Left," Connolly pressed the necessity of "micropolitical engagements on a number of fronts" (1999: 50) that are necessary to reduce economic equality and was critical of "the fantasy of defining a hegemonic position" on the Left (Ibid.: 54), generally being more inclined toward more reflexive "identity politics." This is his pluralist assemblage that is "anchored entirely in no single class, gender, ethnic group, creed, or generation" (Connolly 2013: 137). This assemblage should pressure institutions at multiple sites - from churches and universities to media - and attempt to prevent its own vertical and hierarchical integration.

However, Connolly's recent calls for cross-state civic action complicates the preceding rhizomatic scheme. In thinking the present conjuncture, Connolly's implicit orientation toward internally unstable and dynamic political universalism becomes more pronounced. First, a "bracing event is probably needed to spark the actions because it enables us to translate the diffused sense that concerted action is needed into embodied interconstituency drives to act" (Connolly 2017b: 144). One of course cannot help but wonder whether COVID-19 is not a perfect example of such an event (whether and to what extent it is a missed opportunity for the democratic Left in various countries is another issue). Second, "the interlocking constituencies may need a beacon to help orient our energies and actions" (Connolly 2013: 194). Might this beacon be some guiding image of a better and more just and egalitarian future that embraces biocultural plurality and simultaneously brings us right to the issue of political universality? After all, a beacon is supposed to illuminate and clarify vision. Additionally, in Aspirational Fascism, written and published in 2017 in the wake of Donald Trump's election, Connolly is more vocal about the urgent need to reach the working-class constituencies that lack any "viable counterideal" to the right-wing reaction in America and probably elsewhere. Now, he is more explicit about his ethics including the "ideological element" (Connolly 2017a: 85) and tries to marry his general theorizing of a democratic pluralist ethos with a viable 
counterideal, resulting in what he calls "multifaceted socialism" (Ibid.: 112).

What kind of politics is this? It is certainly on the Left - the specter of socialism is something most liberals and conservatives are eager to exorcise. At the same time, its utopian aspirations throughout the whole field of pragmatic concerns brought about by the Anthropocene, this conjuncture of a self-propelling "conjunction" between planetary fragility and predatory capitalism. Here, that critical responsiveness to difference within one's identity that preoccupied Connolly thirty years ago turns into a potentially universalizing critical response to the increasing shocks at the intersection of politics and nature. Ideally, this politics is more responsive to the Anthropocene's fragility than the one that draws its consistency from the clearcut distinctions between deliberative, communitarian, and agonistic democracies of the "end of history" age. Thus, he imagines what Jedediah Purdy calls "a democracy open to post-human encounters with the living world" (2015: 288). Yet, as we have seen, it requires a lot of coordinated and organized work: deep attention, universalizing counterideals, and, ultimately, some form of a socialist project. One suspects that Connolly would have made things easier had he emphasized a more implicit transcendence within his own immanent naturalism - as well as "multidegree" negativity that fully discloses itself in the zone of transition from ontology to politics.

To think with Connolly and partially against him, we should summarize the whole argument. As we saw, Connolly continuously pushes his agonistic democratic ethics in the direction of a naturalist ontology. He seeks to affirm this ethics' continuity and relevance by grounding it in immanent naturalism that highlights how cultural politics is necessarily overdetermined by bodily sensations, affective flows, and nonhuman events. However, with the growing recognition of the political stakes of climate change and environmental degradation, something changes (or, to borrow the words of Naomi Klein, changes everything). It is thinking this conjuncture politically, as something that dramatically increases planetary fragility, potentially to the point of annihilating this planet, this fragility and all politics, which makes possible to loosen the grip on one privileged mode of action (in this case, ethical micropolitics). To put it differently, this politics now responds to critical zones and situations at the intersection of nature and culture and devises its strategies, models of action, and organization in this response (for instance, instead of applying ready-made transcendentalist schemata). In a paradoxical way it is both pragmatic and revolutionary - pragmatic because it derives its legitimacy from the analyses and practical responses to the concrete 
crises of the Anthropocene and revolutionary to the extent that the capitalist power- and resource-hungry machine constantly appears as something that produces these crises.

However, do we not end up here with some kind of speculative metapolitics that secretly aims to restore the lost vitalist immanence and thus appears as something essentially conservative? Certainly not: although Connolly holds some romantic and neopagan yearnings within himself, the theoretical pattern that we discerned and modified by putting more stress on inherent negativity within socalled natural/cultural immanence simply states that nothing could have been lost in the first place. Complete biocultural immanence is a retroactive apolitical illusion that political theory dispenses with in its thinking the conjuncture. Accordingly, it is not metapolitics in the sense that this politics is mediated by certain extra-political events and crises that carry within themselves a particular pragmatics (for instance, when a politicized environmental issue is eventually resolved through techno-scientific manipulation with active citizen control), and its own structures of inequality and injustice that must be accounted for and addressed within the unfolding of these events. There is, however, much speculation involved. At the same time, we might think of the way the Giletes Jaunes, this invisible and angered minority of French rural dwellers on whom the burden of "greening" the economy was imposed, led to innovations in democratic decision-making: citizen assemblies on climate change, new pragmatic encounters between citizens and experts, and the use of sortition. Additionally, one can note how the leftist climate movements in the US and the EU have legitimated the (macropolitical) projects of their respective New Deals or have gained inspiration from the indigenous environmental movements. These are, of course, only scattered examples within the liberal world of global capitalism. Yet, political theory might think of them as prospective traits of the conjuncture in which multiple interstate, intrastate, governmental, movement-based, indigenous, and other strategies might coalesce and form new democratic constellations in response to the increasing shocks and crises of the Anthropocene.

\section{Conclusion}

In this article, we have attempted to think how political theory is forced to question its ontological foundations with regard to contemporary climate crisis that is frequently theorized via the notion of the Anthropocene. Starting from the continuity of democratic thought with its range of established signifiers, that is, 


\section{Dmitry Lebedev}

deliberation, populism, pluralism, and agonism, we have investigated how the Anthropocene functions as a force of discontinuity in this theoretical tradition. William Connolly's work was chosen as a paradigmatic case, displaying the need to think together both this continuity and discontinuity by opening up political theory to the ontological questions of nonhuman and natural elements disrupting traditional modalities of politics and political theorizing. By tracing Connolly's intellectual trajectory, we have explored how his gradual engagement with these questions, in our case unified through the amalgamated notion of planetary fragility, led him to more attentive interventions in the current political conjuncture. It was precisely in the constant oscillation between refined ontology and political theory that his general focus on the ethico-political pluralism of identities/differences started shifting to the plurality of forms of political actions and organizations with a view to the structural negation the conjuncture that render planetary fragility increasingly catastrophic. Connolly's case demonstrates how continuity within political theory lies not in continuous adherence to specific models of political action, expressed as either agonistic ethics, deliberation, or populist movement. Rather, it is revealed in the very act of thinking new and radical ontological ruptures and discontinuities as discontinuities in the habits and modes of thinking and responses to political conjunctures - and as the opening to the hitherto undertheorized combinations of political activity.

\section{References}

Althusser, Louis (1999). Machiavelli and Us. Trans. Gregory Elliott. London: Verso.

Connolly, William E. (1985). “Taylor, Foucault, and Otherness.” Political Theory 13.3: 365-76.

Connolly, William E. (1993). “Voices from the Whirlwind.” In In the Nature of Things: Language, Politics, and the Environment, eds. Jane Bennett and William Chaloupka, 197-225. Minneapolis: The University of Minnesota Press.

Connolly, William E. (1995). The Ethos of Pluralization. Minneapolis: The University of Minnesota Press.

Connolly, William E. (1999). “Assembling the Left.” Boundary 2 26.3: 47-54.

Connolly, William E. (2002a). Identity/Difference: Democratic Negotiations of Political Paradox [1991]. Minneapolis: The University of Minnesota Press.

Connolly, William E. (2002b). Neuropolitics: Thinking, Culture, Speed. Minneapolis: The University of Minnesota Press.

Connolly, William E. (2013). The Fragility of Things: Self-organizing Processes, Neoliberal Fantasies, and Democratic Activism. Durham, NC: Duke University Press.

Connolly, William E. (2017a). Aspirational Fascism: The Struggle for Multifaceted Democracy under Trumpism. Minneapolis: The University of Minnesota Press.

Connolly, William E. (2017b). Facing the Planetary: Entangled Humanism and the Politics of Swarming. Durham, NC: Duke University Press.

Connolly, William E. (2019). Climate Machines, Fascist Drives, and Truth. Durham, NC: Duke University Press. 


\section{Nature and Philosophy}

Coole, Diana (2000). Negativity and Politics: Dionysus and Dialectics from Kant to

Poststructuralism. London: Routledge.

Deleuze, Gilles (1983). Nietzsche and Philosophy. Trans. Hugh Tomilson. New York: Columbia University Press.

Deleuze, Gilles, and Félix Guattari (1987). A Thousand Plateaus. Trans. Brian Massumi. Minneapolis: The University of Minnesota Press.

Dryzek, John S., and Johnathan Pickering. (2019). The Politics of the Anthropocene. Oxford: Oxford University Press.

James, William (1987). Writings 1902-1910. New York: Library of America.

Johnston, Adrian (2008). Žižek's Ontology: A Transcendental Materialist Theory of Subjectivity. Evanston. IL: Northwestern University Press.

Johnston, Adrian (2014). Adventures in Transcendental Materialism: Dialogues with Contemporary Thinkers. Edinburgh: Edinburgh University Press.

Latour, Bruno (2018). Down to Earth: Politics in the New Climatic Regime. London: Polity.

Leys, Ruth (2011). "Critical Response II. Affect and Intention: A Reply to William E. Connolly.” Critical Inquiry 37: 799-805.

McNay, Lois (2014). The Misguided Search for the Political: Social Weightlessness in Radical Democratic Theory. London: Polity Press.

Mouffe, Chantal (2013). Agonistics: Thinking the World Politically. London: Verso.

Mouffe, Chantal (2020). "Why a Populist Left Should Rally around a Green Democratic Transformation.” OpenDemocracy https://www.opendemocracy.net/en/ rethinking-populism/left-populist-strategy-post-covid-19.

Purdy, Jedediah (2015). After Nature: A Politics for the Anthropocene. Cambridge, MA: Harvard University Press.

Tønder, Lars (2017). “Five Theses for Political Theory in the Anthropocene.” Theory \& Event 20.1: 129-36.

Wenman, Mark (2008). “William E. Connolly: Pluralism without Transcendence.” The British Journal of Politics and International Relations 10.2: 156-70. 